\title{
Tipografia Multidimensional
}

\author{
Multidimensional Typography
}

\author{
Marcelo Gonçalves Ribeiro \\ Universidade Federal do Rio de Janeiro, Brasil \\ marcelogribeiro@ufrj.br
}

\author{
Julie de Araujo Pires \\ Universidade Federal do Rio de Janeiro, Brasil \\ juliepires@ufrj.br
}

\begin{abstract}
This work intends to outline some ways of how typography has been presented, taking into consideration the different configurations type designs may contemporarily take on. In other words, through various approaches and usages, the font drawings are converted into sculptures, paintings, among other things. For this study, the aim is to analyze the path of historical-conceptual contextualization of typography, as well as some of its implications, based on Rosalind Krauss' study on the expanded field.
\end{abstract}

Keywords: Typography; Expanded Field; Bidimensional; Tridimensional; Design.

\section{Introdução}

Tipografia tridimensional, letra poema, tipografia escultural, tipografia fluida, tipografia expressiva: verifica-se diferentes modalidades, algumas relativamente recentes, sinalizando distintos territórios, muitos deles poéticos, quando se pensa no desenho da letra como principal elemento que se estende pelo espaço e por ações experimentais, ampliando um campo conceitual que, antes, nos parecia definido e cristalizado no design gráfico de comunicação visual, mas que, ao contrário, demonstra suas indeterminações.

Tradicionalmente, o design em geral e a tipografia, em particular, são destacados por suas características funcionais e vários trabaIhos que escapam a essa regra não são observados atentamente, considerando sua generalizada ressonância. Os diferentes aspectos que notamos em trabalhos de tipografia que se afastam da tradicional impressão dos tipos parecem apenas um sinal de modismo e de experiências circunstanciais. Porém, esse não reconhecimento daquilo que parece disperso e que não faz parte de uma tradição, não implica, necessariamente, que, estamos diante de algo menor e que, considerando irrelevante, pensaríamos ser meIhor desviar nosso olhar. Podemos pensar que essas obras "híbridas" nos instigam por algum motivo e, por esta razão, seria válido analisá-las e renovar nosso olhar crítico sobre esses trabalhos.

Imersos em um meio movediço que forma o continente hoje chamado tipografia, os conceitos usuais nos escapam. Certamente, transitaremos em um campo poético da letra que, diferentemente das tipografias tradicionais, visam expressar, difundir e comunicar, por meio de sua forma, alheios à função desejada por alguns, preferem expandir, ampliar, esticar o seu lugar partindo do território bidimensional em direção o espaço tridimensional. Assim, no caso dessas tipografias que superam limites, não se trata apenas de pensarmos na contaminação entre discipli- nas, como arte, design e arquitetura, mas também de refletir sobre a posição central da tipografia no que se refere à sua função tradicionalmente difundida: a legibilidade.

Como tratar essas tipografias quando ao invés de configurarem desenhos de letras que possuem o "objetivo de transmitir uma mensagem do modo mais eficaz possível, gerando no leitor destinatário significações pretendidas pelo destinador" (Niemeyer, 2001, pp.12-13), ou quando se configuram "para honrar seu conteúdo" (Bringhurst, 2005, p. 23), tal como as reconhecemos hoje a partir de sua forma, função e contexto, para serem desconfiguradas da noção comum e tradicional? A tipografia que tratamos não se conforma em apenas "funcionar", como se esta fosse um elemento de leitura objetiva, de maneira isenta, configurando palavras a partir do peso da tinta imposta sobre a superfície. Pelo contrário, esta tipografia é repleta de possíveis significados e provavelmente espera, estampada por vezes na folha de papel, ser vista com outros olhos.

Para um vislumbre sobre esse continente, seria importante sobrepor molduras ou contornos mais definidos em direção a uma contextualização sobre a qual podemos nos delimitar. Notamos que este é um momento propício para delinear algumas aproximações e divagações, sem contudo encerrá-las a um espaço imóvel e estanque: como a estrutura da letra avançou pelo espaço, tornandose multidimensional? Quando estas formas se desenrolam do espaço bidimensional que configuram a letra, deixando de ser tipografia funcional para se tornar um desenho? A que modalidades de tipografias estamos nos reportando?

A partir das recentes tecnologias, foi possível pensar a estrutura da letra, independente de sua mídia, suporte, materialidade, linguagem poética ou funcional, também como um entrecruzamento temporal e espacial. Neste sentido, estamos diante de uma das 
questões fundamentais: seria inerente, quando se pensa nas criações tipográficas e nos seus usos, que o tipo seja pensado apenas como elemento em movimento inaugurando temporalidades?

As tipografias configuram nossa condição de leitura, mas também são puro desenho e traço, revelando, pelo avesso, aquilo que escapa da estrutura sintática da forma da letra.

\section{Tipografia e o Aspecto Multidimensional}

O tratamento idealizado da tipografia funcional nas últimas décadas, em certa medida, refletiu alguns valores descritos por Beatrice Warde no ensaio "A taça de cristal" (Warde in Bierut, Helfand, Heller e Poynor, 2010) condicionando a tipografia como um recipiente que precisa ser puro e neutro, visando apenas apresentar o conteúdo textual. Neste sentido, o uso do tipo estaria fundamentado a partir da principal função: ser "transparente" ou "invisível". Warde defendia sua utilização por meio da legibilidade, indicando que a diferença entre o leitor e o autor é superada com a ajuda de uma leitura facilitada pela ideia da tipografia como um cálice de cristal. Essa definição da tipografia é transformadora do trabalho com tipos em um ofício invisível.

Diante disso, muitos designers e pesquisadores da tipografia pensaram de maneira divergente sobre a escolha e o uso da tipografia e, embora muitos usos desses aspectos tipográficos não ocorram de modo uníssono, a adoção desse pensamento de Warde sobre tipografia se tornou primazia e, de certo modo, tem definido sua idealização: um incomodo no ato da leitura é percebido como o "mau design" e a classificação do "bom design" como aquele que, muitas vezes, se apresenta de modo "invisível" para o espectador, visando a legibilidade.

Por um lado, o ensaio de Warde, somado aos discursos oriundos das escolas de design ao longo do século $X X$ e a proclamação de uma nova tipografia, dedicada à idade moderna e sua difusão posterior, que podem ser vistos como reação a uma abordagem mais experimental da tipografia que ocorreu no início do século 20, quando dadaístas, futuristas (anos 20-30) e, mais tarde, a poesia concreta (anos 50-60), explorou os limites da tipografia e o habitual uso do grid cartesiano, voltados à reprodução gráfica. A partir dessas experiências de ruptura com o grid, algumas composições tipográficas tiveram como resultado imagens flutuantes, o uso figurativo das letras e o tratamento tipográfico fragmentado.

Antes mesmo do uso de computadores na criação de projetos gráficos, é possível afirmarmos que a tipografia nunca pôde ser classificada apenas por seu aspecto bidimensional, ligado aos ideais de legibilidade. Essas indeterminações são notadas por alguns autores, entre eles, Spiekermann:

“...embora as formas básicas de nossas letras não tenham mudado muito em centenas de anos, tem havido milhares de variações sobre o tema. As pessoas têm criado alfabetos a partir de figuras humanas, elementos de arquitetura, flores, árvores, ferramentas e todo o tipo de objetos cotidianos para serem usados como iniciais ou como ornamentos tipográficos." (Spiekermann, 2011, p.31)

Na relação com a arte, Pablo Picasso e Georges Braque, introduziram palavras por meio de colagens, a partir de títulos das notícias dos jornais selecionados e recortados. Por outra via, podemos citar o trabalho de Philip Guston em seus "poem-pictures", mesclando poemas com desenhos, evidenciando a relação entre palavra e imagem.

O autor Roland Barthes observa a concepção dos desenhos de letras criados por Erté (Romain dc Tirtoff), a partir do corpo feminino, no qual cada letra criada em seu alfabeto representa uma relação entre feminilidade e a silhueta da escrita. As letras criadas por Erté, segundo Barthes, possuem um mesmo significante com dupla visão: "a mulher ou a letra, e, também, o elo entre as duas". (Barthes, 1990, p.111).

No Brasil, podemos enfatizar o trabalho de Tide Hellmeister, ao considerar projetos com o uso da tipografia moderna deslocada de sua função de leitura. Hellmeister foi profissional da TV Excelsior, onde atuou em diversas atividades ligadas à arte, desde cenografia a desenho de letras para as aberturas e encerramentos dos programas da emissora. Por meio de suas obras, ele buscou enfatizar o tipo a partir de desenho e colagem, conforme afirma Claudio Rocha:

"em suas colagens, as letras deixam de ser signos a serviço do significado, e sua imagem acústica é isolada em um entorno provocantemente excessivo (...) distante de suas funções cognitivas e de leitura, formas inesperadas, figurativas, ou não, preenchem e conformam as letras, emprestando-lhes um caráter pictórico pessoal e intransferível."(Rocha in Hellmeister, 2006, pp.106-107)

O uso da letra em trabalhos de diversos artistas, como no alfabeto de Erté, nos criadores da poesia visual, nos cartazes de MoholyNagy, Saul Bass, entre outros, no campo da arte, do design e do cinema, demonstrou o potencial de uma tipografia expressiva, que explora os limites de seu uso tradicional. Porém, não é possível negar que com a inserção do computador na atividade criadora de designers e artistas, outras possibilidades puderam ser exploradas de maneira mais intensa.

Atualmente, letras e textos são cada vez mais produzidos e veiculados em uma variedade de ambientes e meios de comunicação: telas ou displays de dispositivos, espaços públicos e privados, difundidos por smartphones, computadores ou outros meios digitais. Nosso argumento é que nos envolvemos e experimentamos uma visualidade da tipografia que não necessariamente diz respeito apenas à função da leitura textual.

As frequentes interações proporcionadas pelo uso da tipografia em diferentes plataformas, como a internet, além do uso da tipografia, muitas vezes lúdicas, nas novas mídias, produz um "novo leitor", ou seja, um leitor que apesar de estar envolvido no uso clássico da tipografia, considerando a metáfora de Warde da taça 
de cristal, também é leitor de uma performance da letra que clama pelo usuário que seja também um criador, da tipografia mediada pela tecnologia a partir de softwares e ferramentas mais simples (como o software Livetype) ou do uso dos recursos 3D em softwares tradicionalmente identificados como 2D (como o Adobe Illustrator, por exemplo).

Como marco dessas transformações, notadas no uso da tipografia, podemos destacar a conferência de ATypi, em 1975 em Varsóvia, na qual uma empresa sediada em Hamburgo, apresentou o Ikarus, primeiro sistema digital de design de tipos. (Meggs, 2009) A partir deste momento, vivenciamos um acelerado desenvolvimento da tecnologia envolvendo tipografia digital, que transformou a criação e o uso dos tipos acessível a todos. O que permitiu grande agilidade no processamento de textos e na realização de layouts, garantindo a qualidade da apresentação tipográfica em diferentes equipamentos e mídias.

O computador, como ferramenta cotidiana do designer, levou a tipografia para diferentes interfaces, superando os limites da página impressa em direção ao vídeo, entre outras mídias digitais, permitindo constituir um meio em si mesmo para experiências interativas com textos, numa exploração da escrita digital, do hipertexto, das multitessituras realizadas de modo linear ou multidimensionais.

Assim, a tipografia planejada para um ambiente tridimensional envolve, também, etapas específicas a este ambiente virtual, onde os designers precisam pensar em ferramentas distintas da tipografia convencionalmente planificada. Deste modo, há a necessidade de adotar técnicas como a criação de mapas e retopologia da maIha, que lançam novos olhares para a tipografia e sua tradição.

Um dos pioneiros na arte computacional e no campo de design, por meio do uso da tipografia é John Maeda, cujo trabalho representa um atraente ensaio visual que prescindiu o emprego de recursos gráficos $3 \mathrm{D}$ de alta resolução. Maeda elaborava sua arte por meio de um conjunto de formas bidimensionais, uma paleta de cor básica e restrita, mouse e teclado. Deste modo apresentava uma série de experimentos em tipografia, interativos e animados, inseridos no contexto de uma poesia visual.

Diversos trabalhos de John Maeda se fundamentam no uso do computador tendo em vista explorar a imagem da tipografia e não a sua função. Um projeto de calendário interativo, por exemplo, foi desenvolvido para o usuário clicar a partir dos meses, como um menu para guiá-lo para cada seção. Este calendário se apoia no aspecto visual e não na sua utilização funcional, foco principal de Maeda, conforme o autor afirma em seu livro, "Maeda @ media":

“ao projetar a capa de um livro intitulado 'Dinamic Form', eu criei um fragmento de software para preencher densamente a imagem da capa com dez mil palavras. Esse processo me interessou mais do que o próprio livro e me fez criar muito mais visuais neste estilo programático". (Maeda, 2000, p.27)
O uso da tipografia em outros contextos também foi elaborado por Takenobu Igarashi. A partir de uma série de esculturas projetadas por ele, na década de 1980, explorou características multidimensionais da tipografia, transformando letras em esculturas, construídas pelas dobras do aço ou por curvas em bronze, que ressaltavam uma massa de ângulos e planos geométricos. E, podemos citar, ainda, na mesma época, o trabalho realizado pelo estúdio Pentagram Design, que apresentava o esboço de uma escultura na janela do edifício Time-Life, em Londres, a princípio uma forma abstrata, mas que quando visto de determinado ponto de vista, podia ser lido como diversas palavras. E, também, o trabalho de Paula Scher, em Bloomberg, no qual milhares de números enchiam todo o espaço arquitetônico do salão principal, conduzindo a estrutura arquitetônica como um suporte para a tipografia.

Contudo, alguns projetos demonstram que é necessário compreender ainda mais esta complexidade do uso da tipografia, notando toda sua potencialidade, no sentido de impedir um único termo ou categoria para definí-la. E, para isso, nos parece que um outro recurso teórico é necessário no sentido de envolver esta complexidade.

\section{A noção de campo ampliado}

Inicialmente, buscaremos trazer algumas definições que permitirão uma compreensão mais ampla do termo tipografia, propondo aqui, por meio desta reflexão, ajudar a localizar uma noção de tipografia a partir de um olhar contextualizado em sua história e sua lógica, além de fornecer uma maneira de pensar sobre a tipografia no cenário atual. Essa é uma das maneiras de evitar a precoce desconsideração pelo caminho traçado, partindo de alguns trabalhos em tipografia. E, assim, voltar-se neste momento para a observação de novas perspectivas, ao invés da defesa, recusa ou diminuição da importância de certos trabalhos contemporâneos que utilizam a tipografia dentro e fora do campo do design.

Uma definição tradicional de tipografia, muito difundida na área do design, que podemos citar é a de Jan Tschichold quando diz: "toda tipografia consiste de letras" e a "Tipografia que não pode ser lida por todo o mundo é inútil" (Tschichold, 2007, p.35)

Por outro lado, o que se pretende demonstrar com os trabalhos de diversos autores citados neste artigo, como Igarashi, Maeda, entre outros, é que, na contemporaneidade, a tipografia se move livremente entre alguns polos tradicionalmente opostos, os quais, historicamente, caracterizaram a tipografia como definimos majoritariamente. Entre esses aspectos dicotômicos estão: bidimensional/tridimensional, legibilidade/ilegibilidade, mídia impressa/mídia eletrônica, entre outros. Sob esta ótica, explorar uma complexidade crescente em se definir essas categorias, hoje, significa demonstrar a grande dificuldade em estabelecer setores como design e arte.

Para compreender essas transformações, ocorridas com a noção de tipografia, torna-se necessário uma reflexão teórica mais pro- 
funda e passamos aqui a pensar em um aspecto que poderia nos auxiliar a refletir sobre essas mudanças. Usaremos, então, o conceito elaborado por Rosalind Krauss em 'A escultura no campo ampliado'. Neste texto, a autora enfatiza a questão de que a partir de determinado momento nas artes visuais, coisas que anteriormente não eram caracterizadas como esculturas, passaram a ser entendidas como tal, como exemplifica a autora: corredores estreitos com monitores de TV ao fundo, grandes fotografias documentando caminhadas campestres, espelhos dispostos em ângulos inusitados em quartos comuns, linhas provisórias traçadas no deserto, entre outros. (Krauss,2008)

O campo ampliado, para Rosalind Krauss, é gerado pela problematização do conjunto de oposições, entre as quais está suspensa a categoria modernista de escultura. Por meio dessa via, podemos observar como a tipografia na atualidade, pode ser analisada a partir das noções dessa autora, aglutinando perspectivas muito diferentes. O conceito de ampliação das categorias, apresentado pela autora, pode suscitar certos questionamentos como: o que a tipografia nos parece ser hoje se pensarmos a partir das ideias trazidas pelo campo expandido? Que consequências essa "leitura" da tipografia poderá nos trazer para a compreensão da criação do design nos dias atuais?

O ensaio de Krauss, em 1978 (The expanded field of sculpture) remetia a mudanças que ocorreram na prática artística nas décadas anteriores. A autora observava que o termo escultura parecia apresentar uma "extraordinária demonstração de maleabilidade", tornando-se uma categoria de difícil definição, a partir do momento em que essas manifestações artísticas se tornaram diversas: "era tudo aquilo que estava sobre ou em frente a um prédio que não era prédio, ou estava na paisagem que não era paisagem." (Krauss, 2008, p.132).

Por meio desse ensaio, a autora nos mostrava uma "condição de negatividade" que localizava a escultura em um conjunto de exclusões. A definição de "campo expandido" desta autora remete a um gráfico, que busca apresentar uma expansão de dois termos definidos a partir da palavra escultura. Deste modo, um dos campos reflete a oposição original (escultura = não é isso e não é isso), que ao mesmo tempo define e provoca um alargamento do termo.

O "campo expandido" é gerado pela problematização de conjuntos de pares de opostos, entre os quais "escultura" é apenas uma das definições que formam o campo: escultura, não-paisagem, "marked-sites", paisagem, "site-construction", arquitetura, estruturas axiomáticas, não-arquitetura. Isto impacta também nas definições de arte e artista, identidade e comunidade, que se mostram, então, limitadas e redutoras. Neste contexto, Rosalind Krauss ao perceber que o termo escultura tornara-se obscuro por abranger diferentes categorias, enfatizou que "escultura" não era uma categoria universal, mas sim uma categoria ligada à história e assim, como qualquer outro tipo de convenção, teria sua própria lógica interna, seu conjunto de regras

\section{Tipografias em transformação}

Ao levarmos em consideração o pensamento dessa autora, como poderemos refletir sobre a tipografia contemporânea? Em que medida o uso de tipos em letreiros de neon, esculturas tipográficas, mobiliário na formas de letras do alfabeto, entre outros, se tornou transversal ao seu conceito tradicional, ou seja, forjou um espaço onde diferentes modos de ver podem se encontrar?

A partir do ensaio de Rosalind Krauss podemos, então, explorar as diferentes categorias relacionadas à tipografia, buscando ampliar sua compreensão. Ao considerarmos essa expansão, é possível compreender que uma única abordagem crítica que explore a funcionalidade da tipografia a partir de sua funcionalidade, ou legibilidade, não é mais possível. Torna-se evidente, então, que alguns destes trabalhos se localizam num entrelugar e que o espaço conceitual da tipografia encontra-se expandido, ultrapassando o conceito tradicional, ligado a um momento histórico do termo tipografia.

Pode-se considerar, inicialmente, que o termo tradicional de tipografia está entre um não desenho e um não objeto, ou seja, "A tipografia é uma arte em si mesma e diferente de ambas [a litografia ou o desenho]" (Tschichold, 2007, p. 34) e esta tipografia também é a impressão dos tipos, mas não é o próprio tipo, objeto que possui tridimensionalidade e que se caracteriza como peça móvel, permitindo a impressão da tipografia (tinta sobre papel). Por outro lado, mesmo sendo derivada da escrita manual, a tipografia não é essa escrita, mas busca claramente criar uma oposição ao desenho (como ilustração ou figuração bidimensional).

Mas, se compreendermos o termo tipografia como um espectro, poderemos aceitá-lo entre esses dois pontos extremos e absolutos: objeto (tridimensional) considerando ou não o movimento em oposição ao desenho (bidimensional). Assim como faz Krauss, ao pensar em ampliar esse termo e, em vez de sustentar os opostos, nossa proposta é incorporar um par que inclui os termos opostos e bipolares, formando assim um triângulo. Temos, então, os dois aspectos de que carece a tipografia (vértice inicial).

Os opostos bipolares organizados e apoiados ao termo tipografia formam um triângulo. Essa forma básica é utilizada por Krauss para determinar as dimensões lógicas que formam a base para que a noção de "historicidade" do termo ajuda a apresentar, mais claramente para nós, uma maneira de organização e, no caso da escultura, demonstra que esse triângulo inicial abrange termos e lógicas diferentes e não apenas um único termo isolado. No caso do termo da tipografia, a este vértice, estão associados dois polos negativos: não é um objeto ou não é um desenho.

Podemos identificar práticas artísticas que usam a tipografia e percebemos que a noção de tipografia tem sido 'esticada' desde a década de 1960, tanto em ação prática como em termos lógicos para designar áreas de atividades de design (como vídeo e mídias digitais). A tipografia expandida, considerando os binários de exclusão apresentados a partir do ensaio de Krauss, pode ser consi- 
derada desenho, mas também a própria escultura tridimensional do tipo móvel.

Ainda a partir do raciocínio da autora, podemos incorporar a cada vértice, que chamaremos de "não é objeto" e "não é desenho", outros dois vértices como seus reflexos imediatos, ou seja: objeto e desenho. Deste modo formamos um retângulo, que podemos imaginar o local no qual encontramos um "campo ampliado" para a tipografia.

Entre desenho e não-desenho pode-se encontrar as experiências tipográfcas de Erté, o Grafite; manuscrito, iluminuras, entre outros. Vuk Cosic, importante artista da net.art, realizou, por meio de código ASCII, ferramenta considerada de baixa tecnologia, releituras de filmes como King Kong, Star Trek, Garganta Profunda, Blow up em formato ASCII. Nessas obras, Cosic realiza um entrelaçamento entre texto e imagem, época em que "as possibilidades de representação de imagens com o computador eram limitadas". (Lieser, 2010, p.156)

Entre o não objeto e o objeto, surgem letras esculturais como, por exemplo, "Alphabot", criada por Nikita Pashenkov, no The Media Lab do MIT. A obra consiste num robô virtual que pode assumir a forma de qualquer letra do nosso alfabeto. Ele foi construído para participar de uma competição em tipografia do "Tokyo Type Director's Club", em 2000. (Pashenkov, 2013)

O objeto e o não objeto são dois aspectos distintos, não presentes na noção tradicional de tipografia, uma vez que esta não poderia ser tridimensional, à medida que esse é um campo do tipo móvel distinto do seu resultado: a impressão da letra. A tipografia construída em softwares cad e os letreiros em neon também podem se situar mais próximos a este vértice, assim como podemos incluir nesta área, o trabalho do designer londrino Johnson Banks, como o projeto "Arkitypo", um alfabeto tridimensional como forma de experimentação das ferramentas de prototipagem de seus clientes.

Entre desenho e objeto podemos localizar as experiências tipográficas de Mizuki Ohno, designer gráfico criador de "Jiodori Bunko" (Dance Letters Library), trabalho experimental que inclui uma série animada de 16 páginas em flipbook. E, outro exemplo neste campo é o alfabeto completo da designer Ben Loiz, desenvolvido para a revista "Swindle", no qual a forma das letras surge a partir de diferentes entrelaçamentos de elásticos, que se formam a partir de corte, montagem e dobras. Imagens fotográficas dos elásticos, sob luz incidente remete a estruturas tridimensionais, que vistas por ângulos alternados, criam formas orgânicas inesperadas. (Reyes, 2007, p.18)

\section{Conclusão}

Neste trabalho buscamos além de apontar uma contaminação mútua entre os vários modos como a tipografia se apresenta hoje, quando o artista-designer assume um papel multidisciplinar, também refletir sobre uma renúncia ao papel central da tipografia como elemento operacional da função de leitura.
É importante destacar o pensamento de John Maeda no sentido da nossa frequente resistência a mudanças, impondo a novas formas ideias já estabelecidas:

"Por causa dos pressupostos, das tradições da arte e do design, em usar um material único em posição fixa, nosso instinto crítico reduz qualquer coisa variável em um único instante. A única solução é sempre escolher (esse instante), porque um pedaço de papel, plástico, ou de pedra não pode assumir simultaneamente várias formas. Um material estático impõe um processo de pensamento com uma única conclusão. Assim, é difícil apreciar e, mais importante, avaliar uma mudança no estado da arte. A reação natural é impor a forma um congelamento - para que possa assumir um único instante. Mas um outro instinto apoia a nossa vontade de deixá-lo seguir - quando percebemos que há vida." (Maeda, 2000, p.64)

Artistas, como Maeda, Igarashi, Tide Hellmeister, Erté, entre outros, liberaram-se do peso do historicismo: a letra deslocada de sua 'função' de leitura, dá 'voz' a outras camadas como o desenho, objeto, não desenho e não objeto, multiplicando-se diante do nosso olhar e tornando-se interdisciplinar.

\section{Referências}

BARTHES, Roland. O óbvio e o obtuso. Rio de Janeiro: Nova Fronteira, 1990.

BIERUT, Michael et.al. Textos clássicos do design gráfico. São Paulo: Editora WMF Martins Fontes, 2010

BRINGHURST, Robert. Elementos do Estilo Tipográfico. São Paulo: Cosac Naify, 2005.

HELLMEISTER, Tide. Tide Hellmeister: inquieta colagem. Curitiba, PR: infolio Editorial, 2006.

KRAUSS, Rosalind. A escultura no campo ampliado. In: Arte \& Ensaios. Revista do Programa de Pós-graduação em Artes Visuais EBA/UFRJ, Rio de Janeiro, n. 17, 2008. Pp.128-137.

LIESER, Wolf. Arte digital: novos caminhos na arte. Tandem Verlag GmbH. 2010.

MAEDA, John. MAEDA@MEDIA. Thames \& Hudson, London, 2000.

MEGGS, Philip B. História do Design Gráfico. São Paulo: Cosac Naify, 2009.

MILLER, J. Abbott. Dimensional typography. New York: Princeton Architectural Press, 1996.

NIEMEYER, Lucy. Tipografia: uma apresentação. 4. ed. Rio de Janeiro: 2AB, 2010.

PASHENKOV, 2013. In:http://acg.media.mit.edu/people/nik/ e http://www.ratstar.com/

REYES, Fabiola. Typo, fuente de inspiración. Barcelona: Instituto Monsa de Ediciones, 2007.

SPIEKERMANN, Erik. A linguagem invisível da tipografia: escolher, combinar e expressar com tipos. São Paulo: Blucher, 2011.

TERSTIEGE, Gerrit (org). Three D :graphic spaces. Basel, Switzerland; Boston :Birkhauser, 2009.

TSCHICHOLD, Jan. A forma do livro. São Paulo: Ateliê Editorial, 2007. 